\title{
Early clinical manifestations of vibrio necrotising fasciitis
}

Thean Howe Bryan Koh${ }^{1}$, MBBS, Jiong Hao Jonathan $\underline{T a n}^{1}$, MBBS, MRCS, Choon-Chiet Hong${ }^{1}$, MBBS, MRCS, Wilson Wang ${ }^{1,2}$, FRCS, DPhil, Aziz Nather $^{1}$, FRCSE, FAMS

ABSTRACT We present five patients with vibrio necrotising fasciitis, a lethal and disabling disease. Two of these patients had a history of exposure to either warm seawater or raw/live seafood, three had underlying chronic liver disease, and four presented with hypotension and fever. There were three deaths and four patients required intensive care unit stays. Among the two survivors, one had high morbidity. Only one patient met the criteria of Laboratory Risk Indicator for Necrotising Fasciitis score $>6$. A clinician should suspect possible vibrio necrotising fasciitis if the following are present: contact with fresh seafood/warm seawater, a known history of chronic liver disease and pain that is out of proportion to cutaneous signs. All patients must be managed via intensive care in high dependency units. We recommend a twostep surgical protocol for patient management involving an initial local debridement, followed by a second-stage radical debridement and skin grafting.

Keywords: LRINEC score, outcome, treatment, vibrio necrotising fasciitis

\section{INTRODUCTION}

Vibrio vulnificus ( $V$. vulnificus) is a Gram-negative halophilic marine bacillus that is found in warm seawater and on shellfish and crustaceans. It proliferates in warm coastal environments. The number of patients diagnosed with vibrio necrotising fasciitis has been reported to be on the increase due to a rise in sea surface temperatures. ${ }^{(1)}$ This is especially relevant for Singapore, which is both warm and coastal. Despite increasing clinical awareness and advancements in antibiotic and infection management algorithms, vibrio necrotising fasciitis still remains a lethal and disabling disease. We present five patients with vibrio necrotising fasciitis who were treated at National University Hospital, Singapore, between 2005 and 2014 (Table I) and highlight pertinent points that could help to achieve a favourable treatment outcome in these patients.

\section{CASE SERIES}

\section{Patient 1}

A 61-year-old Malay woman with a history of Child-Pugh Class A hepatitis $C$ virus liver cirrhosis and coronary artery disease presented with a two-day history of severe left medial thigh pain and swelling that was associated with fever and tachycardia. The patient had no prior history of trauma or contact with seafood or seawater. On examination, her left thigh was swollen and extremely tender, with blistering and purple erythema. She underwent urgent magnetic resonance (MR) imaging of the left thigh. MR imaging showed increased short tau inversion recovery $(\mathrm{STIR}) / \mathrm{T} 2$ signal and free fluid in the fascial planes, which was suggestive of necrotising fasciitis (Fig. 1). However, the patient's Laboratory Risk Indicator for Necrotising Fasciitis (LRINEC) score was 3. Her blood and wound cultures were both positive for V. vulnificus. She underwent emergency left thigh debridement and fasciectomy, with intraoperative findings of 'dishwater' fluid and necrotic fascia. Postoperatively, she was admitted to the

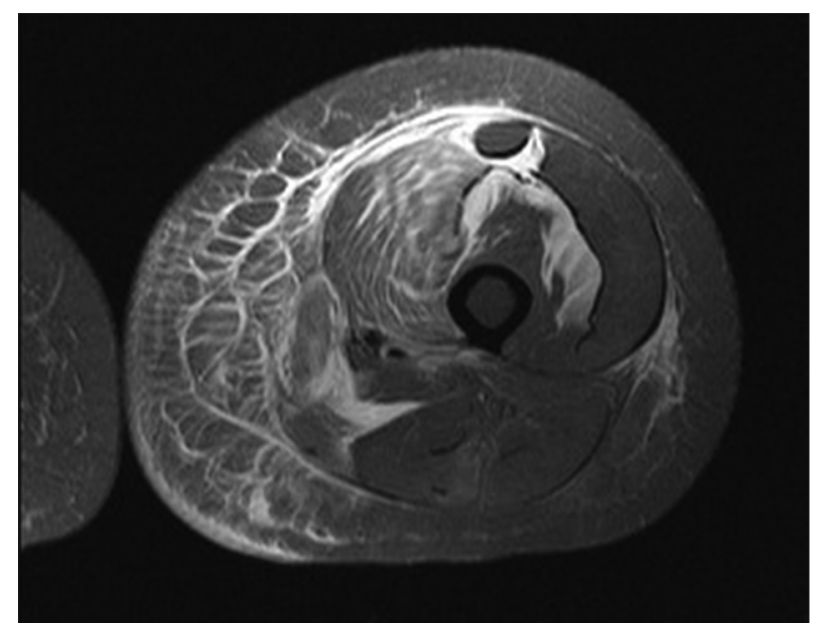

Fig. 1 Patient 1. Multiplanar MR image of the left thigh shows extensive subcutaneous stranding and oedema with enhancement. STIR/T2 high signal suggests fluid within the deep/intermuscular fascial planes, predominantly along the anterior and medial compartments of the left thigh. The image also shows mild, patchy, deep/intermuscular fascial enhancement.

intensive care unit (ICU), where her condition was complicated by acute renal failure and subsequent multiorgan failure. She was pronounced dead on postoperative Day 5 despite maximal resuscitative efforts.

\section{Patient 2}

A 65-year-old Chinese man with a history of poorly controlled diabetes mellitus, hypertension and hyperlipidaemia presented with a two-day history of bilateral upper limb rash and blistering associated with fever, after cleaning his boat. On examination, the patient was drowsy and hypotensive (blood pressure $78 / 48 \mathrm{mmHg}$ ), and his right forearm was warm, tender and grossly indurated with blistering extending from the right forearm to the lateral aspect of the arm. Due to his unstable condition, he was 
Table I. Summary of patients diagnosed with vibrio necrotising fasciitis.

\begin{tabular}{|c|c|c|c|c|c|c|c|c|c|c|c|}
\hline No. & $\begin{array}{l}\text { Age }(y r) / \\
\text { gender/ } \\
\text { ethnicity }\end{array}$ & Medical history & Symptoms & $\begin{array}{l}\text { Mean duration } \\
\text { of symptoms } \\
\text { (day) }\end{array}$ & $\begin{array}{l}\text { Mode of } \\
\text { infection }\end{array}$ & $\begin{array}{l}\text { Blood/tissue } \\
\text { culture } \\
\text { findings }\end{array}$ & $\begin{array}{l}\text { LRINEC } \\
\text { score }\end{array}$ & $\begin{array}{l}\text { Type of initial } \\
\text { operation }\end{array}$ & $\begin{array}{l}\text { No. of } \\
\text { procedures }\end{array}$ & $\begin{array}{l}\text { Length of } \\
\text { hospital } \\
\text { stay (day) }\end{array}$ & $\begin{array}{l}\text { Patient } \\
\text { outcome }\end{array}$ \\
\hline 1 & $\begin{array}{l}\text { 61/female/ } \\
\text { Malay }\end{array}$ & $\begin{array}{l}\text { Child-Pugh Class A } \\
\text { hepatitis C virus } \\
\text { liver cirrhosis and } \\
\text { coronary artery } \\
\text { disease }\end{array}$ & $\begin{array}{l}\text { Severe left medial } \\
\text { thigh pain and swelling } \\
\text { associated with fever and } \\
\text { tachycardia }\end{array}$ & 2 & Unknown & V. vulnificus & 3 & $\begin{array}{l}\text { Emergency } \\
\text { left thigh } \\
\text { debridement and } \\
\text { fasciectomy }\end{array}$ & 1 & 5 & Death \\
\hline 2 & $\begin{array}{l}65 / \text { male/ } \\
\text { Chinese }\end{array}$ & $\begin{array}{l}\text { Poorly controlled } \\
\text { diabetes mellitus, } \\
\text { hypertension and } \\
\text { hyperlipidaemia }\end{array}$ & $\begin{array}{l}\text { Bilateral upper limb } \\
\text { rash and blistering } \\
\text { associated with fever, } \\
\text { drowsiness, tachypnoea } \\
\text { and hypotension }\end{array}$ & 2 & $\begin{array}{l}\text { Cleaning } \\
\text { of boat }\end{array}$ & V. vulnificus & 7 & $\begin{array}{l}\text { Emergency } \\
\text { right upper limb } \\
\text { debridement and } \\
\text { fasciectomy }\end{array}$ & 15 & 120 & $\begin{array}{l}\text { Discharged } \\
\text { after } 3 \text { mth } \\
\text { with multiple } \\
\text { complications }\end{array}$ \\
\hline 3 & $\begin{array}{l}53 / \mathrm{male} / \\
\text { Chinese }\end{array}$ & $\begin{array}{l}\text { Hepatitis B virus } \\
\text { carrier, poorly } \\
\text { controlled } \\
\text { diabetes mellitus, } \\
\text { hypertension and } \\
\text { hyperlipidaemia }\end{array}$ & $\begin{array}{l}\text { Left ankle and leg } \\
\text { pain and swelling } \\
\text { associated with fever and } \\
\text { hypotension }\end{array}$ & 1 & Unknown & $\begin{array}{l}\text { Vibrio } \\
\text { cholerae }\end{array}$ & 3 & $\begin{array}{l}\text { Emergency } \\
\text { left lower limb } \\
\text { debridement and } \\
\text { fasciectomy }\end{array}$ & 3 & 37 & $\begin{array}{l}\text { Discharged } \\
\text { after } 37 \text { days }\end{array}$ \\
\hline 4 & $\begin{array}{l}83 / \text { male/ } \\
\text { Chinese }\end{array}$ & $\begin{array}{l}\text { Hypertension and } \\
\text { hyperlipidaemia }\end{array}$ & $\begin{array}{l}\text { Pain and swelling of the } \\
\text { dorsum of the left hand } \\
\text { up to the olecranon, } \\
\text { associated with fever, } \\
\text { hypotension, tachycardia, } \\
\text { metabolic acidosis, } \\
\text { acute renal failure and } \\
\text { coagulopathy }\end{array}$ & 2 & $\begin{array}{l}\text { Pricked } \\
\text { by a live } \\
\text { crab }\end{array}$ & V. vulnificus & 6 & $\begin{array}{l}\text { Left above-elbow } \\
\text { amputation }\end{array}$ & 1 & 2 & Death \\
\hline 5 & $\begin{array}{l}67 / \text { female/ } \\
\text { Chinese }\end{array}$ & $\begin{array}{l}\text { Hepatitis B virus } \\
\text { carrier }\end{array}$ & $\begin{array}{l}\text { Bilateral lower limb pain } \\
\text { and swelling associated } \\
\text { with fever, tachypnoea } \\
\text { and hypotension }\end{array}$ & 3 & Unknown & $\begin{array}{l}\text { V. vulnificus } \\
\text { (wound) }\end{array}$ & 4 & $\begin{array}{l}\text { Bilateral } \\
\text { lower limb } \\
\text { debridement and } \\
\text { fasciectomy }\end{array}$ & 8 & 23 & Death \\
\hline
\end{tabular}

LRINEC: Laboratory Risk Indicator for Necrotising Fasciitis; V. vulnificus: Vibrio vulnificus 


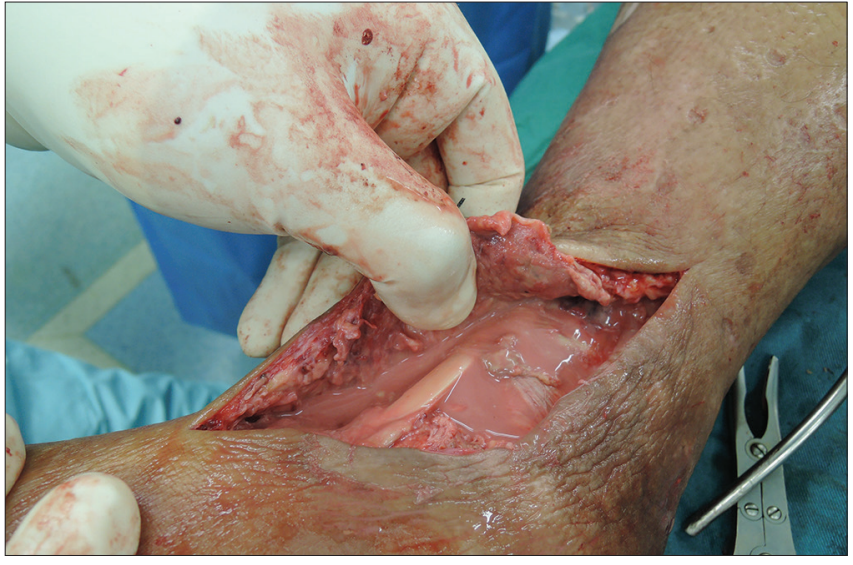

Fig. 2 Patient 3. Photograph shows necrotic fascia and copious amounts of 'dishwater' fluid and pus in the left leg.

unable to undergo MR imaging and was admitted to the ICU. His LRINEC score was 7. The patient underwent emergent right upper limb debridement and fasciectomy for suspected necrotising fasciitis, which confirmed the diagnosis of necrotising fasciitis. His blood culture was positive for $V$. vulnificus. Over the next three months, he underwent multiple further wound debridement. His ICU stay was complicated by ventilator-associated pneumonia, acute respiratory distress syndrome and acute kidney injury. He was discharged after three months.

\section{Patient 3}

A 53-year-old Chinese man, a hepatitis B virus carrier with a history of poorly controlled diabetes mellitus and multiple comorbidities, presented with a one-day history of left ankle and leg pain and swelling associated with fever. There was no history of contact with marine organisms or seawater. On examination, the patient was hypotensive (blood pressure 90/60 $\mathrm{mmHg}$ ) and remained so despite intravenous fluid resuscitation. His left ankle was tender with progressively ascending blistering and erythema. His LRINEC score was 3. The patient underwent emergency fasciectomy (Fig. 2) and multiple lower limb debridement with subsequent skin grafting. His blood and wound cultures were both positive for Vibrio cholerae.

\section{Patient 4}

An 83-year-old Chinese man with no significant past medical history presented with a two-day history of pain and swelling of the dorsum of his left hand that was associated with fever, after getting pricked by a live crab. On examination, the patient had severe hypotension (blood pressure 57/33 mmHg) and tachycardia. There was erythema, skin necrosis and blistering that extended up the dorsum of his hand to the olecranon. The puncture mark was visible and had purulent discharge. His LRINEC score was 6. A diagnosis of necrotising fasciitis was made and the patient was managed with a left above-elbow amputation. His wound culture was positive for V. vulnificus. Postoperatively, he suffered an acute myocardial infarction that was complicated by acute renal failure and coagulopathy, which contributed to his demise despite maximal resuscitative efforts and inotropic support in the surgical ICU.

\section{Patient 5}

A 67-year-old Chinese woman who was a hepatitis B virus carrier presented with a three-day history of bilateral lower limb pain and swelling associated with fever. There was no history of trauma. On examination, she was hypotensive and tachypnoeic. Her bilateral lower limbs were erythematous, oedematous and blistering up to the level of her medial malleoli. Her LRINEC score was 4. She underwent multiple extensive debridement of her lower limbs, which confirmed the diagnosis of necrotising fasciitis, and her blood cultures were positive for $V$. vulnificus. Despite full intensive care support, the patient's condition progressively deteriorated and she died.

\section{DISCUSSION}

Vibrio necrotising fasciitis is a true surgical emergency. Its rapid progression and fulminant course may be related to pathogenderived exotoxins and/or enzymes, which induce vascular permeability changes, systemic inflammatory reactions leading to multiorgan failure, septic shock and even death. ${ }^{(2)}$ Its fulminant clinical presentation has resulted in mortality rates that have been reported to be as high as $25 \%-100 \%$. ${ }^{(3)}$

Vibrio necrotising fasciitis has significant associations with contact with warm seawater and marine organisms. In a study by Tsai et al, (4) $97 \%$ of their patients had a significant history of contact with warm seawater or raw seafood. By comparison, in our study, only two out of five patients $(40 \%)$ were exposed to either warm seawater or raw/live seafood. Given the increasing incidence of vibrio skin and soft tissue infections, especially in coastal waters with high sea surface temperatures (such as in Singapore), public health policies, such as proper storage of seafood at between $0^{\circ} \mathrm{C}$ and $4^{\circ} \mathrm{C}$, can reduce the number and pathogenicity of Vibrio spp. as well as its threat to public health. ${ }^{(5,6)}$

A notable personal history of chronic liver disease has also been reported to be significantly associated with vibrio necrotising fasciitis. ${ }^{(7)}$ This is extremely relevant in Singapore, where the prevalence of hepatitis B virus carriers is $6 \%$, and $20 \%-30 \%$ of these patients are known to progress to liver cirrhosis and/or liver cancer ${ }^{(8)}$ Tsai et al's study also cited that $28 \%$ of patients with vibrio necrotising fasciitis had a history of hepatic dysfunction. ${ }^{(4)}$ In our series, three out of five patients $(60 \%)$ had underlying chronic liver disease - two were hepatitis B virus carriers and one had hepatitis $C$ virus liver cirrhosis.

Vibrio necrotising fasciitis is known to have a fulminant clinical presentation, ${ }^{(2,3)}$ a finding that was evident in our series. Out of the five patients, $4(80.0 \%)$ presented initially to the emergency department with hypotension (blood pressure < 90/60 $\mathrm{mmHg}$ ); the remaining non-hypotensive patient was in impending shock, as reflected by resting tachycardia (heart rate $>110$ beats per minute). All of our patients had fever at presentation. The rapid deterioration in the clinical course of this disease re-emphasises the importance of having a high index of suspicion, early recognition of infection and prompt treatment on the part of clinicians. 
In our series, the mortality rate was high at $60 \%(n=3)$, and $80 \%(n=4)$ of the patients required ICU stay. Among the two patients who survived, one had high morbidity and required inpatient stay for 120 days. This patient (i.e. Patient 2) also underwent 15 surgical procedures, ranging from wound debridement to an eventual right forearm amputation. The average number of procedures in our series was 5.6 per patient and the mean length of hospital stay was 37.4 days.

Hong et al reported on the management of a series of patients diagnosed with vibrio necrotising fasciitis complicated by septic shock initiation, using a two-stage surgical protocol with simple incision and drainage, followed by selective debridement and skin grafting. ${ }^{(1)}$ The mortality of vibrio necrotising fasciitis patients at their institution, which ranged from $41.5 \%$ to $70.6 \%$, was reduced to $37.5 \%$ using this two-stage surgical protocol. In our study, we adopted a similar two-part surgical strategy that involved an initial local debridement of the necrotic fascia and subcutaneous tissue, followed by a second stage of repeated radical debridement and skin grafting. Such an approach may potentially reduce the mortality rate for patients with pre-existing surgical contraindications due to other medical conditions, such as coagulation disorders and shock. ${ }^{(1)}$

The LRINEC score has been shown to be less reliable for diagnosing vibrio necrotising fasciitis. When Wong et al proposed the LRINEC score for diagnosing necrotising fasciitis, they cited a positive predictive value of $92 \%$ when a cut-off LRINEC score $>6$ was used. ${ }^{(7)}$ However, Chao et al, who studied the validity of the LRINEC score for diagnosing vibrio necrotising fasciitis, found that the mean LRINEC score in patients with vibrio necrotising fasciitis was $3.3(p<0.0001) .^{(2)}$ Similarly, Tsai et al found that $89 \%$ of patients with vibrio necrotising fasciitis had an LRINEC score $<6 .{ }^{(4)}$ These findings are very similar to that of our series, where only one of five patients with vibrio necrotising fasciitis met the criteria of LRINEC score $>6$.
In conclusion, for the prevention of vibrio-related necrotising fasciitis, proper storage of seafood at the correct temperatures must be strictly enforced and implemented to prevent the proliferation of bacteria. A high index of suspicion is required on the part of clinicians for the early diagnosis of vibrio necrotising fasciitis. Relevant indicators in the patient's clinical history include contact with fresh seafood/warm seawater and a known medical history of chronic liver disease. Pain that is out of proportion to cutaneous signs is another important indicator that should be noted during physical examination. We recommend that all patients diagnosed with vibrio necrotising fasciitis be managed intensively in a high dependency care unit. In addition, we advocate a two-step surgical protocol for the management of these patients that involves an initial local debridement, including excision of all necrotic fascia and subcutaneous tissue, followed by a second stage of repeat radical debridement and skin grafting.

\section{REFERENCES}

1. Hong G, Wu B, Lu C, et al. Emergency treatment of 16 patients with necrotizing fasciitis caused by Vibrio vulnificus infection complicated with septic shock. Chin Med J (Engl) 2014; 127:1984-6.

2. Chao WN, Tsai SJ, Tsai CF. The Laboratory Risk Indicator for Necrotizing Fasciitis score for discernment of necrotizing fasciitis originated from Vibrio vulnificus infections. J Trauma Acute Care Surg 2012; 73:1576-82.

3. Tsai YH, Hsu RW, Huang KC, Huang TJ. Laboratory indicators for early detection and surgical treatment of vibrio necrotizing fasciitis. Clin Orthop Relat Res 2010; 468:2230-7.

4. Tsai YH, Wei-Wei Hsu R, Huang KC, Huang TJ. Comparison of necrotizing fasciitis and sepsis caused by Vibrio vulnificus and Staphylococcus aureus. J Bone Joint Surg Am 2011; 93:274-84.

5. Huang KC, Weng HH, Yang TY, et al. Distribution of fatal Vibrio vulnificus necrotizing skin and soft-tissue infections: a systematic review and meta-analysis. Medicine (Baltimore) 2016; 95:e2627.

6. Mahmud ZH, Neogi SB, Kassu A, et al. Occurrence, seasonality and genetic diversity of Vibrio vulnificus in coastal seaweeds and water along the Kii Channel, Japan. FEMS Microbiol Ecol 2008; 64:209-18.

7. Wong CH, Khin LW, Heng KS, Tan KC, Low CO. The LRINEC (Laboratory Risk Indicator for Necrotizing Fasciitis) score: a tool for distinguishing necrotizing fasciitis from other soft tissue infections. Crit Care Med 2004; 32:1535-41.

8. $\mathrm{H}^{\prime} \mathrm{Ng}$ MW, Chew WY, Tan BK. Necrotizing fasciitis caused by Vibrio vulnificus: a review of four cases in a Singapore tertiary hospital. J Trauma 2005; 59:482-5. 